\title{
A Case of Thyroid Papillary Carcinoma: Remarkable Decrease in Multiple Lung Metastases within 40 Years after a Single Administration of Radioiodine without Thyroidectomy and with Later Anaplastic Transformation
}

\author{
Chio Okuyama ${ }^{a, b}$ Mitsuhiro Kimura ${ }^{c}$ Minori Oda ${ }^{b, d}$ Naohiro Kodani ${ }^{b, e}$ \\ Norihiro Aibe ${ }^{b}$ Hideya Yamazaki ${ }^{b}$ \\ ${ }^{a}$ Shiga Medical Center, Research Institute, Moriyama, Japan; ${ }^{b}$ Department of Radiology, \\ Graduate School of Kyoto Prefectural University of Medicine, Kyoto, Japan; 'Department \\ of Otorhinolaryngology, Shimane Prefectural Central Hospital, Izumo, Japan; ${ }^{d}$ Image \\ Communication Corporation, Kyoto, Japan; ${ }^{~}$ Department of Radiology, Kyoto Second Red \\ Cross Hospital, Kyoto, Japan
}

\section{Keywords}

Children · Pulmonary metastasis · Thyroid carcinoma · Long-term survival · Radioiodine therapy $\cdot$ Anaplastic transformation

\section{Abstract}

Differentiated thyroid carcinoma is an uncommon malignancy of childhood and adolescence that is unique because it has an overall favorable prognosis despite its relatively high rate of nodal and distant metastases. Total thyroidectomy and positive ${ }^{131}$ I therapy are recommended for cases with pulmonary metastases. In contrast, anaplastic thyroid cancer is one of the 


\section{Case Reports in Oncology}

Case Rep Oncol 2017;10:928-937

DOI: $10.1159 / 000481500$

(C) 2017 The Author(s). Published by S. Karger AG, Basel www.karger.com/cro

Okuyama et al.: A Case of Thyroid Papillary Carcinoma

most aggressive malignancies that have an unfavorable and miserable prognosis. We report a case with an impressively long history. The patient had multiple pulmonary metastases that had been diagnosed by ${ }^{131} \mathrm{I}$ administration when he was 14 years old, about 45 years before he underwent thyroidectomy. He had been kept unaware of his disease by his family and received no treatment for most of his life. Pulmonary nodules were noted at several medical checkups and showed a remarkable decrease in size during the untreated 44-year period after the ${ }^{131} \mathrm{I}$ administration. At age 58, his thyroid cancer was first detected and total thyroidectomy was performed, with subsequent radioiodine therapy for pulmonary metastases. Unfortunately, anaplastic carcinoma developed and he died of disseminated tumors later.

(C) 2017 The Author(s)

Published by S. Karger AG, Basel

\section{Introduction}

Differentiated thyroid carcinoma in childhood and adolescence is an uncommon malignancy and unique as to its overall favorable prognosis despite its relatively high rate of nodal and distant metastases [1-3]. Total thyroidectomy and positive ${ }^{131}$ I therapy are recommended for cases with pulmonary metastases. In contrast, anaplastic thyroid cancer is one of the most aggressive malignancies with a poor prognosis. It is thought that anaplastic cancer arises from transformation of differentiated thyroid cancer; however, the mechanism of dedifferentiation remains unclear $[4,5]$.

We experienced a case of differentiated thyroid carcinoma with pulmonary metastases that remarkably decreased in size over a 40 -year period after early administration of ${ }^{131}$ I for diagnosis without thyroidectomy. At age 58, the patient's cervical nodules were incidentally detected, and total thyroidectomy was performed along with subsequent administration of radioiodine therapy (RIT). Although very intense accumulations were observed in both lungs, some of the nodules developed in anaplastic transformation over the next several years. We report the long history of this case and discuss the relevant literature.

\section{Case Report}

\section{History from the Patient's Adolescent Period}

In 1960, a 12-year-old male was hospitalized in Shimane because a chest X-ray revealed multiple nodules in both lungs. Although he had no apparent symptoms, such as cough, high fever, or lethargy, he was assumed to have pulmonary miliary tuberculosis and received anti-tuberculosis therapy. Despite 2 years of therapy, the lung nodules continued growing, but he was doing well in general and developed no symptoms.

His family doctor doubted the clinical diagnosis of tuberculosis and consulted a specialist. The specialist recommended performing a ${ }^{131}$ I scintiscan to rule out the presence of metastatic lung tumors from thyroid cancer. In the 1960s, ${ }^{131}$ I scintiscans were not common and were only performed at one institution in Japan. The patient traveled to Tokyo to undergo the examination in 1962. After the examination, he returned to Shimane, and his medical treatment for tuberculosis was stopped because the ${ }^{131}$ I scintiscan had revealed that his 


\section{Case Reports in Oncology}

Case Rep Oncol 2017;10:928-937

DOI: $10.1159 / 00048150$

(C) 2017 The Author(s). Published by S. Karger AG, Basel www.karger.com/cro

Okuyama et al.: A Case of Thyroid Papillary Carcinoma

pulmonary nodules were associated with thyroid cancer. Though his family doctor prescribed some medication, he quit taking the medicine, which caused him palpitation. In Japan patients were seldom informed that they had malignant tumors at that point of time; therefore, his father kept his son from being informed about his own disease. The patient grew up several decades without receiving any medication and led a typical life before his thyroid nodules were noted at a medical checkup. His thyroid carcinoma was resected at age 59 in 2006. Before that, multiple pulmonary nodules showed up many times in medical checkups including chest X-rays. However, further investigations were not performed because he knew that he had a history of multiple asymptomatic pulmonary nodules over a long time. Only one bronchoscopic examination that he underwent when he was 35 years old failed to confirm the diagnosis.

Since the first diagnosis had been made in the early 1960s, the medical records were no longer available. However, old letters from his doctor passed to the patient's father and an old chest X-ray retained by his father that were kept in his old house were found incidentally in his father's room in 2008 and revealed the details about the patient's past history.

\section{History of the Patient's Present Illness}

At age 58, in 2006, the patient's thyroid tumor and cervical lymphadenopathy were detected using ultrasonography at a health check screening. Total thyroidectomy and radical left neck dissection were performed, and the cancer was diagnosed as papillary carcinoma. $\mathrm{X}$-ray and computed tomography (CT) of the chest revealed multiple fine nodules in both lungs (Fig. 1b). His serum thyroglobulin (Tg) level was $586 \mathrm{ng} / \mathrm{mL}$ even after the thyroidectomy; therefore, multiple pulmonary metastases from thyroid cancer were strongly suspected. However, it was necessary to clarify whether the miliary lung nodules were the metastatic disease from thyroid cancer or postinflammatory scars, because at that time he believed that he had a past history of miliary tuberculosis. A diagnostic ${ }^{131}$ I whole body scan (131IWBS) was performed at Kyoto Prefectural University Hospital.

At the ${ }^{131} \mathrm{I}-\mathrm{WBS}$, he was asymptomatic, and no pulmonary rale was audible on careful examination. After 2 weeks of L-thyroxine withdrawal and an iodine-free diet, ${ }^{131}$ I scintigraphy was performed 2 days following the administration of capsules totaling $111 \mathrm{MBq}$ of ${ }^{131} \mathrm{I}-$ $\mathrm{NaI}$. Very intense accumulation was seen in both lungs, and small hot spots indicating metastatic lesions in the left supraclavicular region and in the thyroid bed remnant were found (Fig. 2). Subsequently, 3,700 MBq of 131I was administered for treatment.

After the patient had received RIT at age 58, the fine nodular pulmonary lesions showed only slight decrease, and his serum Tg level had dropped to between 150 and $250 \mathrm{ng} / \mathrm{mL}$. Since the Tg level remained still quite high, additional 131I therapy was recommended, which the patient refused because he knew that he had carried the multiple pulmonary nodules for more than 45 years without suffering any symptoms, as he had discovered his father's secret letters that described the illness as having originated in the 1960s. He was convinced that the past detail-uncovered radioiodine administration in Tokyo had provided a dramatic decrease of his pulmonary nodules during several decades and expected a similar efficacy.

In 2008, his serum $\mathrm{Tg}$ was still high, and diagnostic ${ }^{131} \mathrm{I}-\mathrm{WBS}$ and ${ }^{18} \mathrm{~F}-$-fluorodeoxyglucose (FDG) positron emission tomography (PET)/CT were performed. 131I-WBS showed that the uptake in both of his lungs had markedly decreased and that the cervical lymph node lesions had disappeared. ${ }^{18 F-F D G ~ a c c u m u l a t i o n ~ w a s ~ n o t ~ s e e n ~ i n ~ t h e ~ l u n g s ~ e x c e p t ~ f o r ~}$ 


\section{Case Reports in Oncology}

Case Rep Oncol 2017;10:928-937

DOI: $10.1159 / 000481500$

(C) 2017 The Author(s). Published by S. Karger AG, Basel www.karger.com/cro

Okuyama et al.: A Case of Thyroid Papillary Carcinoma

small hot spots in the relatively large nodules in his right lung base (Fig. 3), which had not increased in size for 2 years. The follow-up did not include any aggressive treatment other than thyroid-stimulating hormone suppression.

However, in 2011, the patient started developing shortness of breath, and X-ray radiography revealed right pleural effusion. CT revealed a pleural mass of about $5 \mathrm{~cm}$ in diameter in the right diaphragm. Aspiration examination of the effusion confirmed a diagnosis of anaplastic carcinoma. The right pleura was thickened and the nodules of the right lung base had increased, while the other fine nodules were unchanged compared with their sizes from his 2006 records. Systemic chemotherapy and drainage of the effusion with adhesion therapy were started. However, the pleural mass continued growing, and moreover bladder, multiple bone, and brain metastases developed. He eventually died 5 months after the diagnosis of anaplastic carcinoma. The time course of his disease is summarized in Table 1.

\section{Discussion}

Anaplastic thyroid carcinoma has been reported to arise from preexisting differentiated thyroid cancer $[4,5]$. Although some reports have indicated that it may be related to mutation of the $p 53$ gene $[4,6]$, the exact mechanism of anaplastic transformation has not been clarified. There are also some reported cases of anaplastic carcinomas with DNA damage that might have been induced by RIT [5]. However, there are considerably more patients with differentiated carcinomas receiving RIT compared with those who come to have anaplastic carcinoma, so the causal relationship is not widely accepted currently.

In contrast to anaplastic carcinoma, it is universally agreed that differentiated thyroid carcinoma in children and adolescents has a very favorable prognosis. The long-term survival rates are $>95 \%$, despite the relatively high rate of nodal and distant metastases $[1,7]$. Total thyroidectomy and RIT are also recommended for pediatric patients as well as for adult patients with pulmonary metastases $[1,2,8]$.

In our case, disseminated pulmonary nodules had been detected in the 1960s when he was very young, and later they were diagnosed as metastatic tumor from differentiated thyroid cancer by ${ }^{131}$ I scintiscan. The patient grew up without having been informed about the exact diagnosis, undergoing thyroidectomy, or receiving medication. At age 58, a medical checkup led him to know his thyroid cancer and pulmonary metastases. Unfortunately, 5 years after thyroidectomy, RIT, and subsequent thyroid-stimulating hormone suppression with L-thyroxine had started for his thyroid cancer, some nodules came to be anaplastically transformed.

The clinical course of this patient has some interesting and meaningful aspects. After 131I administration in 1962, the dosage of which is unknown, multiple pulmonary metastases showed a marked decrease in size during a period of over 40 years without treatment. There are few reports of cases with multiple pulmonary metastases that were followed over long periods without resection of thyroid tumors. Okada et al. [8] reported the long-term followup of childhood and adolescent thyroid cancers, and in their 5 cases of pulmonary metastases, 2 patients who had not undergone total thyroidectomy died, while the other 3 cases who underwent total thyroidectomy were alive. 


\section{Case Reports in Oncology}

Case Rep Oncol 2017;10:928-937

DOI: $10.1159 / 000481500$

(C) 2017 The Author(s). Published by S. Karger AG, Basel www.karger.com/cro

Okuyama et al.: A Case of Thyroid Papillary Carcinoma

A total or at least subtotal thyroidectomy is thought to be indispensable before RIT for distant metastases, since normal thyroid tissue has a much higher affinity for iodine compared with other metastatic tissues. So, the improvement of one's metastatic nodules by RIT without undergoing thyroidectomy is not usually expected.

Some functioning metastatic lesions of thyroid cancer with thyroid function, which occasionally caused thyrotoxicosis, have been reported [9]. In our case, it is supposed that the thyroid hormone was prescribed after the ${ }^{131}$ I scintiscan in 1962. However, the patient experienced some symptoms of hyperthyroidism and quit taking the medicine. At the histopathological confirmation at the total thyroidectomy in 2006, normal thyroid tissue surrounding the cancer tissue was observed. This may suggest that his metastatic pulmonary lesions had such considerably high iodine affinity equivalent to normal thyroid tissue that a sufficient amount of radioiodine might have accumulated in the lungs without him undergoing thyroidectomy, and the long-lasting irradiation effect had contributed to marked improvement of the lesions.

Another important aspect of this case was that after the RIT in 2006, the 131I accumulation in both lungs decreased, despite the persistently high serum Tg level, and later anaplastic transformation occurred.

Dottorini et al. [7] reviewed 85 cases of differentiated thyroid carcinoma who were younger than 18 years of age at the time of diagnosis, and noted that a high percentage of pulmonary metastases disappeared by ${ }^{131}$ I-WBS after RIT, while a completely undetectable serum Tg level was achieved in only a minority of patients. In some of their cases with persisting high serum Tg levels after RIT despite negative scintigraphic findings, the pulmonary metastases continued to decrease spontaneously even without further therapy. Some other reports have described patients with persistently positive Tg levels that declined or even disappeared over time without treatment [3].

There is no maximum dose limit for cumulative ${ }^{131}$ I given to patients with persistent iodine-avid disease before intolerable toxicity develops or the patient refuses treatment [10]. The guidelines for RIT by the European Association of Nuclear Medicine Therapy Committee state that RIT may be halted in favor of "watchful waiting" for patients with iodine-avid tumors who do not achieve complete response to several radioiodine courses.

In our case, the second diagnostic scan showed that the 131I accumulation had apparently decreased despite the persistently high Tg level. Detectability is influenced by the administered dose of ${ }^{131}$ I [11], and higher therapeutic dose images frequently reveal more tumors than diagnostic low-dose images. Even if accumulation cannot be seen by the treatment dose, disappearance of small lung metastases is often observed [12]. Nobody knows whether another repeated high-dose RIT could have achieved a favorable response.

Unfortunately, our patient developed anaplastic cancer 5 years after RIT at age 58. While metastatic pleural tumors and pleural effusion were observed, most of the pulmonary fine nodules had not changed compared with those observed 5 years before. Only some relatively large nodules of the lung base with FDG avidity in 2008 had showed remarkably rapid growth.

The affinity of FDG-PET in thyroid cancer is thought to have an inverse relationship with the ability of the tumor to concentrate radioiodine [13]. This "flip-flop" phenomenon is recognized depending on the differentiation of the thyroid cancer. When it becomes dedifferentiated, thyroid cancer loses the ability to trap radioiodine [14], and compared with FDG- 
negative lesions, FDG-avid metastatic lesions show significantly higher resistance to highdose RIT [15]. Therefore, lesions with FDG accumulation often indicate relatively aggressive behavior, but this does not always mean anaplastic carcinoma. In our case, after the RIT in 2006, most of the pulmonary nodules had lost their affinity for iodine, but most did not concentrate FDG either. The findings that (1) the anaplastic carcinoma had developed from the right lung base and (2) only some nodules in which FDG had accumulated in 2006 had grown while other nodules remained unchanged are notable.

No one is sure whether the patients could have escaped from the anaplastic transformation if he had undergone total thyroidectomy and subsequent RIT in his childhood, whether the RIT had "woken a sleeping lion" or not, or whether we should have "let sleeping dogs lie" or not. However, this case proposes that the management of asymptomatic thyroid cancers in children and adolescents, who are usually expected to have good long-term prognoses even if they have disseminated disease, may be worth of careful consideration.

\section{Statement of Ethics}

On behalf of all the authors, the first author was given written informed consent to publish the disease history by the patient when he was alive.

\section{Disclosure Statement}

No potential conflict of interest relevant to this article is reported.

\section{References}

1 Hung W, Sarlis NU: Current controversies in the management of pediatric patients with welldifferentiated non-medullary thyroid cancer: a review. Thyroid 2002;12:683-702.

-2 Luster M, Lassmann M, Freudenberg LS, Reiners C: Thyroid cancer in childhood: management strategy, including dosimetry and long-term results. Hormones (Athens) 2007;6:269-278.

3 Caplan RH, Wickus GG, Manske BR: Long-term follow-up of a patient with papillary thyroid carcinoma, elevated thyroglobulin levels, and negative imaging studies. Endocr Pract 2005;11:43-48.

4 Aldinger KA, Samaan NA, Ibanez M, Hill CS Jr: Anaplastic carcinoma of the thyroid: a review of 84 cases of spindle and giant cell carcinoma of the thyroid. Cancer 1978;41:2267-2275.

5 Shingu K, Kobayashi S, Yokoyama S, Fujimori M, Asanuma K, Ito KI, Hama Y, Maruyama M, Kusama R, Amano J: The likely transformation of papillary thyroid carcinoma into anaplastic carcinoma during postoperative radioactive iodine-131 therapy: report of a case. Surg Today 2000;30:910-913.

-6 Fagin JA, Matsuo K, Karmakar A, Chen DL, Tang SH, Koeffler HP: High prevalence of mutations of the p53 gene in poorly differentiated human thyroid carcinomas. J Clin Invest 1993;91:179-184.

7 Dottorini ME, Vignati A, Mazzucchelli L, Lomuscio G, Colombo L: Differentiated thyroid carcinoma in children and adolescents: a 37-year experience in 85 patients. J Nucl Med 1997;38:669-675.

8 Okada T, Sasaki F, Takahashi H, Taguchi K, Takahashi M, Watanabe K, Itoh T, Ota S, Todo S:

Management of childhood and adolescent thyroid carcinoma: long-term follow-up and clinical characteristics. Eur J Pediatr Surg 2006;16:8-13.

-9 Durante C, Haddy N, Baudin E, Leboulleux S, Hartl D, Travagli JD, Caillou B, Ricard M, Lumbroso JD, De Vathaire F, Schlumberger M: Long-term outcome of 444 patients with distant metastases from papillary and follicular thyroid carcinoma: benefits and limits of radioiodine therapy. J Clin Endocrinol Metab 2006;91:2892-2899. 


\section{Case Reports in Oncology}

Luster M, Clarke SE, Dietlein M, Lassmann M, Lind P, Oyen WJ, Tennvall J, Bombardieri E: Guidelines for radioiodine therapy of differentiated thyroid cancer. Eur J Nucl Med Mol Imaging 2008;35:1941-1959.

-11 Arnstein NB, Carey JE, Spaulding SA, Sisson JC: Determination of iodine-131 diagnostic dose for imaging metastatic thyroid cancer. J Nucl Med 1986;27:1764-1769.

12 Schlumberger M, Arcangioli O, Piekarski JD, Tubiana M, Parmentier C: Detection and treatment of lung metastases of differentiated thyroid carcinoma in patients with normal chest X-rays. J Nucl Med 1988;29:1790-1794

13 Bertagna F, Bosio G, Biasiotto G, Rodella C, Puta E, Gabanelli S, Lucchini S, Merli G, Savelli G, Giubbini R, Rosenbaum J, Alavi A: F-18 FDG-PET/CT evaluation of patients with differentiated thyroid cancer with negative I-131 total body scan and high thyroglobulin level. Clin Nucl Med 2009;34:756-761.

14 Wang W, Larson SM, Tuttle RM, Kalaigian H, Kolbert K, Sonenberg M, Robbins RJ: Resistance of [18F]fluorodeoxyglucose-avid metastatic thyroid cancer lesions to treatment with high-dose radioactive iodine. Thyroid 2001;11:1169-1175.

15 Frilling A, Gorges R, Tecklenborg K, Gassmann P, Bockhorn M, Clausen M, Broelsch CE: Value of preoperative diagnostic modalities in patients with recurrent thyroid carcinoma. Surgery 2000;128: 1067-1074.
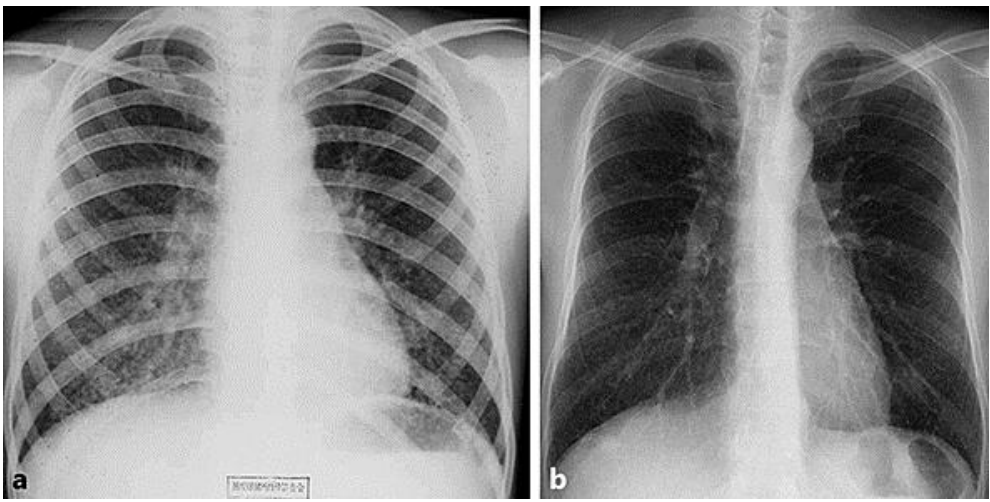

Fig. 1. Chest X-rays taken at the age of 12 years (a) and 58 years (b). a At 12 years, multiple pulmonary nodules were noted, which were diagnosed as miliary tuberculosis. b At 58 years, fine pulmonary nodules were observed; however, they were smaller than those observed in 1962. 


\section{Case Reports in Oncology}

Okuyama et al.: A Case of Thyroid Papillary Carcinoma

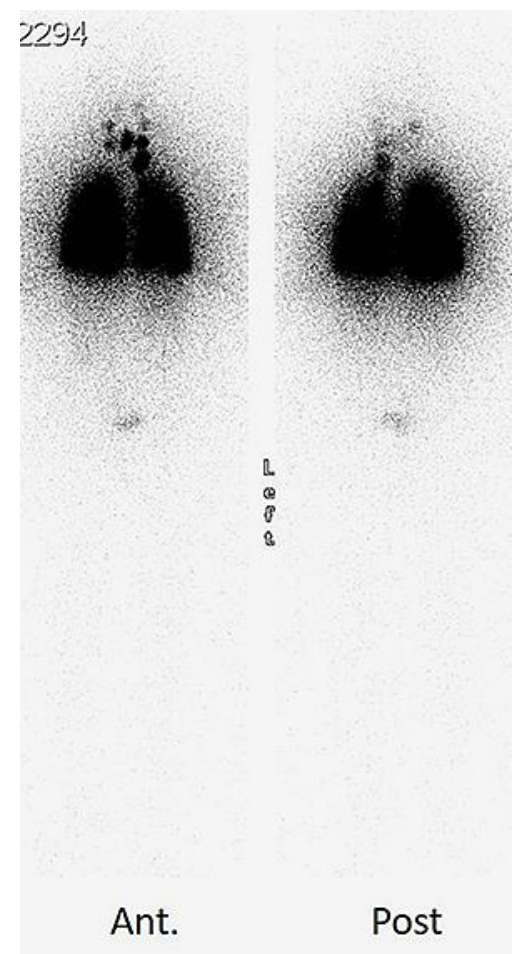

Fig. 2. 131I scintigrams after administration of the diagnostic dose after total thyroidectomy at 59 years. Both lungs had intense accumulation of radioiodine, which suggested that there were multiple metastatic lesions of differentiated thyroid cancer. Thyroid bed and left supraclavicular lymph node lesion were also visualized. 


\section{Case Reports in Oncology}

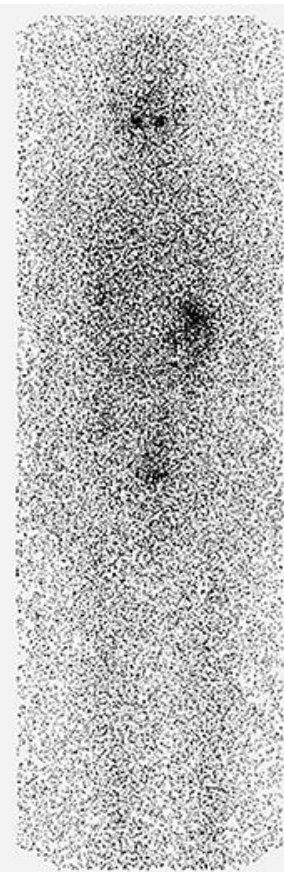

a

Ant.

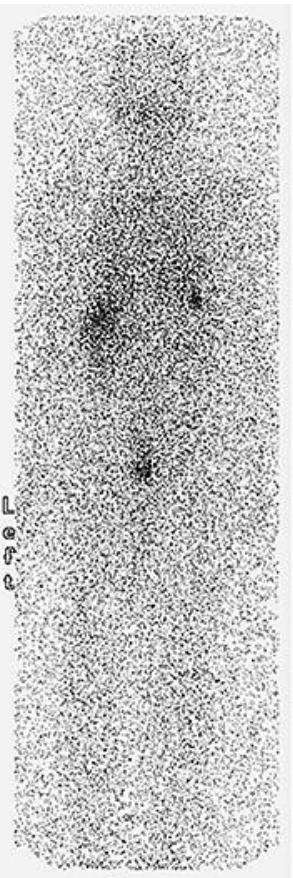

Post

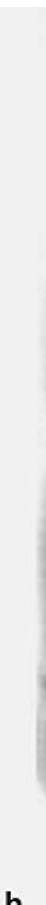

b (c) 2017 The Author(s). Published by S. Karger AG, Basel www.karger.com/cro

Okuyama et al.: A Case of Thyroid Papillary Carcinoma

Fig. 3. 131I whole body scan (131I-WBS) and ${ }^{18} \mathrm{~F}$-fluorodeoxyglucose positron emission tomography/computed tomography (FDG-PET/CT) performed in 2008. a 131I-WBS. b Maximum intensity projection image of FDG-PET. $\mathbf{c}$ CT of the lung base. $\mathbf{d}$ FDG-PET of the lung base. The affinity to FDG appeared to be low in most of the lung nodules. Only mild accumulations were observed in the relatively large nodules in the right lung base. 
Table 1. Time course of the patient's disease history

\begin{tabular}{|c|c|c|c|}
\hline Year & Age & Examination findings and diagnosis & Treatment \\
\hline 1960 & 12 & $\begin{array}{l}\text { multiple pulmonary nodules } \\
\Rightarrow \text { Dx: miliary tuberculosis }\end{array}$ & anti-tuberculosis therapy \\
\hline 1962 & 14 & $\begin{array}{l}\text { radioiodine administration } \\
\Rightarrow \text { Dx: pulmonary mets from thyroid cancer } \\
\text { (the patient was not told the diagnosis) }\end{array}$ & no medication ${ }^{1}$ \\
\hline 1983 & 35 & $\begin{array}{l}\text { bronchoscopic examination } \\
\Rightarrow \text { it failed to confirm the diagnosis of the multiple } \\
\text { lung nodules }\end{array}$ & \\
\hline 2006 & 58 & $\begin{array}{l}\text { medical checkup found the cervical tumors } \\
\Rightarrow \text { Dx: papillary thyroid carcinoma } \\
\text { 131I scintigraphy } \\
\Rightarrow \text { Dx: pulmonary and lymph node mets }\end{array}$ & $\begin{array}{l}\text { total thyroidectomy } \\
\text { radical neck dissection } \\
131 \text { I therapy }(3,700 \mathrm{MBq})\end{array}$ \\
\hline 2008 & 60 & $\begin{array}{l}131 \text { I diagnostic scan } \\
\Rightarrow \text { only little accumulation in the lungs } \\
\text { FDG-PET } \\
\Rightarrow \text { mild accumulation in only the lung base } \\
\text { high serum thyroglobulin value }\end{array}$ & $\begin{array}{l}\text { thyroid-stimulating } \\
\text { hormone suppression } \\
\text { therapy }\end{array}$ \\
\hline 2011 (May) & 63 & $\begin{array}{l}\text { pleural effusion and large pleural mass } \\
\Rightarrow \text { Dx: anaplastic carcinoma }\end{array}$ & $\begin{array}{l}\text { chemotherapy } \\
(\text { CDDP + DOC) }\end{array}$ \\
\hline (July) & & $\begin{array}{l}\text { bladder tumor } \\
\Rightarrow \text { Dx: metastatic anaplastic carcinoma }\end{array}$ & $\begin{array}{l}\text { transurethral resection; } \\
\text { chemotherapy (DOC) }\end{array}$ \\
\hline $\begin{array}{l}\text { (August) } \\
\text { (October) }\end{array}$ & & $\begin{array}{l}\text { multiple brain tumors } \\
\text { bone tumor (Th1) } \\
\text { death }\end{array}$ & $\begin{array}{l}\text { radiation therapy } \\
\text { radiation therapy }\end{array}$ \\
\hline
\end{tabular}

${ }^{1}$ After the radioiodine administration, the patient was maybe given thyroid hormone for a while. FDG, fluorodeoxyglucose; mets, metastases; PET, positron emission tomography. 